\title{
Hypertrophic osteoarthropathy in renal cell carcinoma \\ - A case report -
}

\section{Kyung Seo Oh, Seung Young Lee, Se-Hee Min, Choongun Ryu, and Hwa-Yong Shin}

Received December 1, 2020

Revised March 16, 2021

Accepted March 16, 2021

\section{Corresponding author}

Hwa-Yong Shin, M.D., Ph.D., FIPP, CIPS

Department of Anesthesiology and

Pain Medicine, Chung-Ang University

Hospital, 102 Heukseok-ro, Dongjak-

gu, Seoul 06973, Korea

Tel: 82-2-6299-3164

Fax: 82-2-6299-2585

E-mail: pain@cau.ac.kr
Department of Anesthesiology and Pain Medicine, Chung-Ang University Hospital, Seoul, Korea

Background: Hypertrophic osteoarthropathy ( $\mathrm{HOA})$ is a rare clinical condition including an abnormal periosteal reaction in the long bones that causes painful swelling and tenderness of the extremities, digital clubbing, arthritis, synovitis, and joint effusions. Most cases are associated with tumorous conditions and most commonly with lung cancer. HOA has been rarely reported in association with other cancers.

Case: A patient with a history of recurrent renal cell carcinoma was referred to our clinic with bilateral leg pain, knee joint effusion, and arthritis. Simple radiography and bone scintigraphy confirmed a diagnosis of HOA. Oral non-steroidal anti-inflammatory drugs, joint fluid aspiration, and intra-articular injection of pain medications were found to be effective in the management of HOA pain.

Conclusions: HOA prognosis depends on the underlying disease, therefore, cancer treatment is critical. This case demonstrates the need to consider HOA in patients with various malignancies who present with bone or joint pain of the extremities.

Keywords: Paraneoplastic syndrome; Periostitis; Renal cell carcinoma; Scintigraphy; Secondary hypertrophic osteoarthropathy.
Hypertrophic osteoarthropathy (HOA) is a rare clinical condition including an abnormal periosteal reaction of the long bones that causes painful swelling and tenderness of the extremities, digital clubbing, arthritis, synovitis, and joint effusions [1]. Primary HOA is an autosomal dominant hereditary disease and represents only $3 \%$ of all cases [2]. Secondary HOA is predominantly associated with tumorous conditions and primarily with lung cancer [3]. HOA has been rarely reported as a paraneoplastic syndrome associated with various malignancies including gastrointestinal, hematologic, nasopharyngeal, melanoma, breast, and renal cell cancer $[3,4]$. In one study, only two out of 30 patients presented with HOA caused by renal cell cancer (6.7\%) [4].
Here, we review the diagnosis and treatment of an atypical case of HOA in a patient with recurrent renal cell cancer.

\section{CASE REPORT}

The patient was informed and has provided written consent for the publication of this case report.

A 53 year old man was referred to our pain clinic for painful bilateral lower leg swelling, which began 1 month earlier. On presentation, his pain severity was $6-8 / 10$ on the visual analogue scale (VAS). He had a past medical history of renal cell carcinoma diagnosed 3 years ago and radical nephrectomy of the left kidney. After 1 year, he was found to have re-

This is an Open Access article distributed under the terms of the Creative Commons Attribution Non-Commercial License (http://creativecommons.org/licenses/by-nc/4.0) which permits unrestricted non-commercial use, distribution, and reproduction in any medium, provided the original work is properly cited.

Copyright (c) the Korean Society of Anesthesiologists, 2021 
current renal cell carcinoma and underwent chemotherapy. Moreover, he underwent a left hemicolectomy 1 year ago because of a metastatic lesion in the descending colon.

Physical exam revealed fluid shifting, tender swelling, and painful limitation of range of motion of both knees, suggesting joint effusion (Fig. 1). Digital clubbing was not present. To find the cause of the painful lower leg swelling, simple radiologic studies from the pelvis to the feet and whole body bone scintigraphy with Tc-99m hydroxymethylene diphosphonate were performed. Periosteal reactions were observed in both tibias, fibulas, and femurs on simple radiologic studies (Fig. 2). Bone scintigraphy revealed increased radiotracer uptake along the cortex of the appendicular bones (Fig. 3). Although the digital clubbing was not present, we could diagnose hypertrophic osteoarthropathy based on periosteal reactions found on X-rays and bone scintigraphy.

The patient was prescribed naproxen $1,000 \mathrm{mg} / \mathrm{d}$ for pain. An ultrasound guided therapeutic arthrocentesis of both knees was performed. Clear, yellowish joint fluid was aspirated from both knees (right $4 \mathrm{ml}$, left $12 \mathrm{ml}$ ). After the arthrocentesis, both knees were intra-articularly injected with

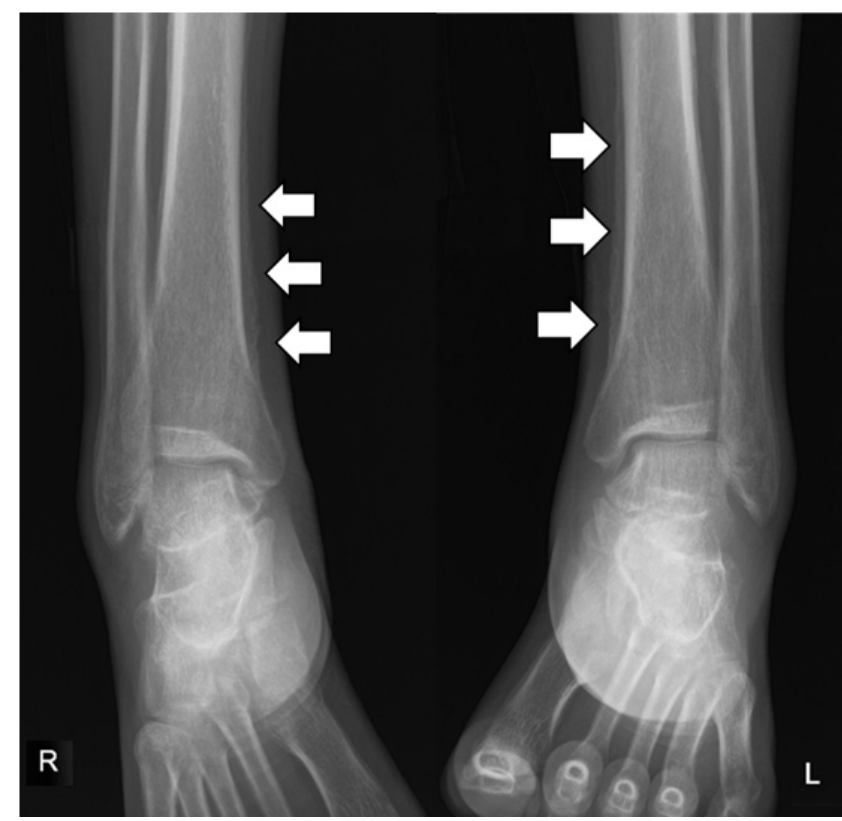

Fig. 2. Simple radiologic studies of the patient's feet. A bilateral periosteal reaction indicates hypertrophic osteoarthropathy (arrows).

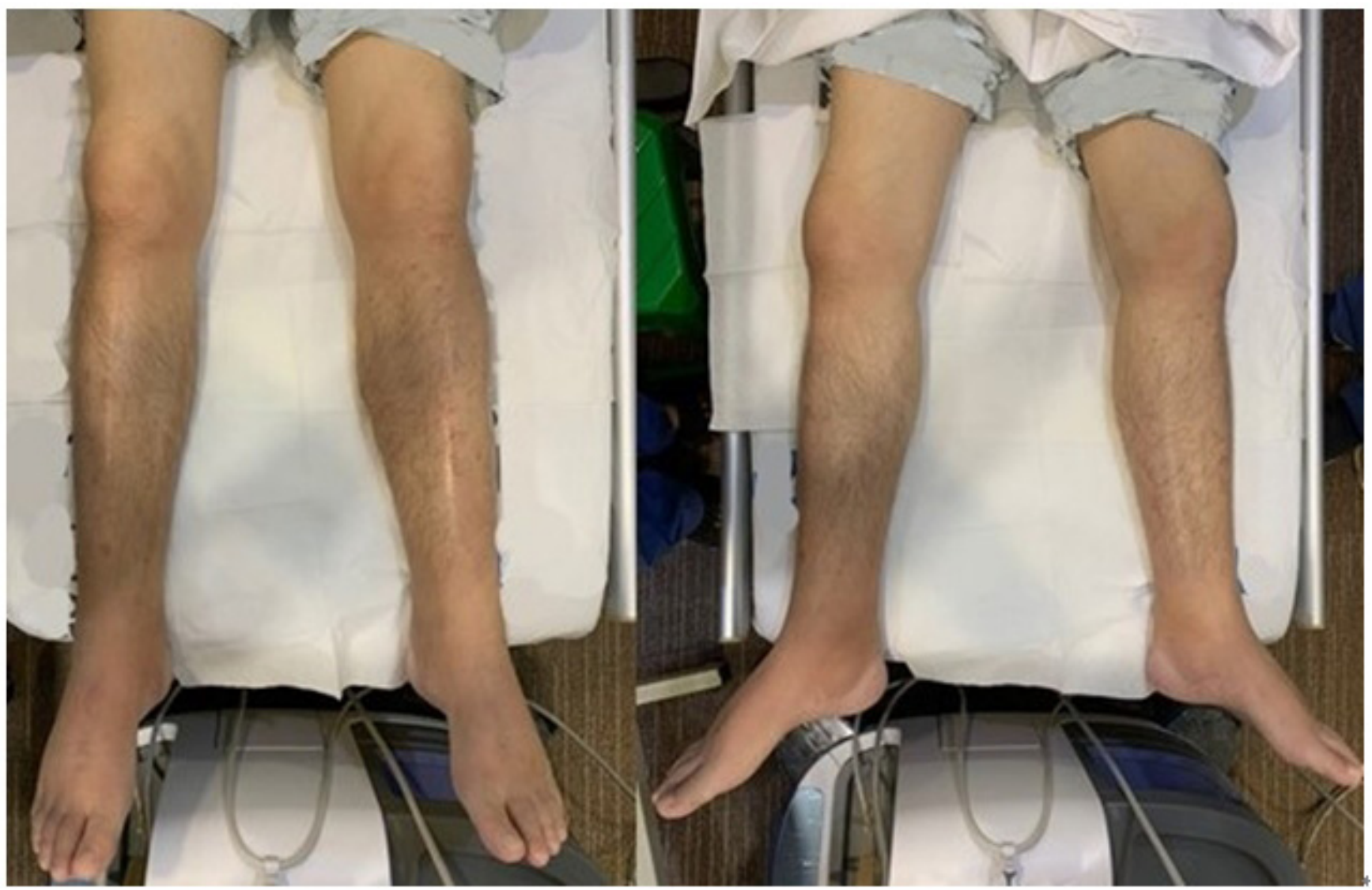

Fig. 1. Photographs of the patient's legs. Bilateral swelling is observed from above the knees to the feet. 
a mixture of $1 \mathrm{ml}$ ropivacaine, $0.75 \mathrm{mg} / \mathrm{ml} ; 2 \mathrm{ml}$ sodium hyaluronate, $10 \mathrm{mg} / \mathrm{ml}$; triamcinolone acetonide $10 \mathrm{mg}$; and morphine sulfate $0.5 \mathrm{mg}$.

At 1-week follow-up, the pain was greatly reduced from VAS $6-8 / 10$ to $1-2 / 10$. At the patient's request, another ultrasound guided therapeutic arthrocentesis was performed, with $2 \mathrm{ml}$ and $3 \mathrm{ml}$ of joint fluid aspirated from the right and left knee, respectively. Subsequently, a mixture of $1 \mathrm{ml}$ ropivacaine, $0.75 \mathrm{mg} / \mathrm{ml} ; 2 \mathrm{ml}$ sodium hyaluronate, $10 \mathrm{mg} / \mathrm{ml}$; triamcinolone acetonide $10 \mathrm{mg}$; and morphine sulfate $1 \mathrm{mg}$ was injected in each knee joint. The patient showed no side effects after arthrocentesis and injection.

The patient is undergoing chemotherapy for treatment of his renal cell cancer. Non-steroidal anti-inflammatory drugs

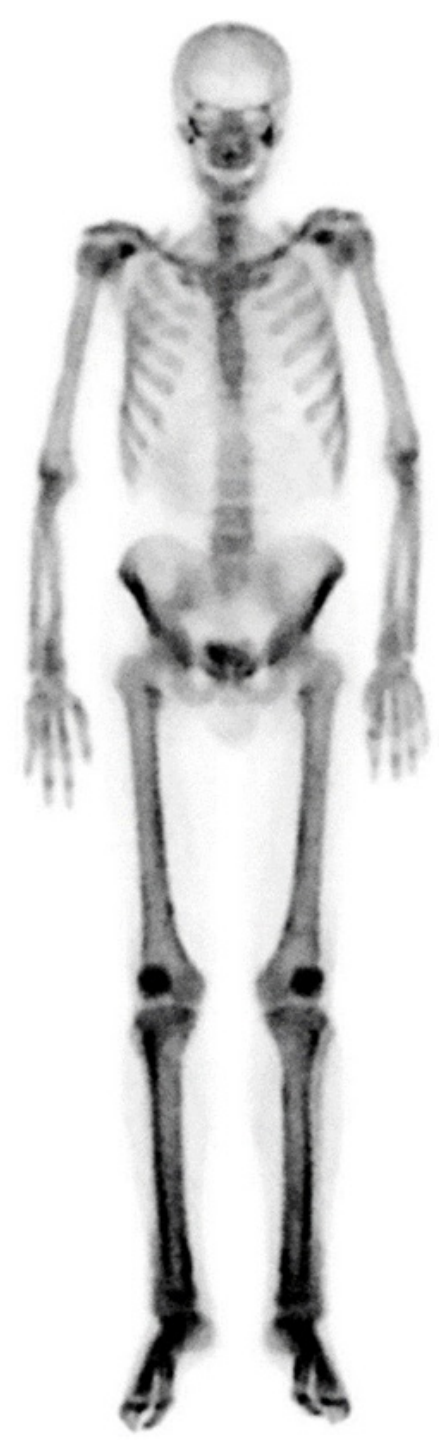

Fig. 3. Whole body bone scintigraphy. Increased radiotracer uptake is observed along the appendicular bone cortex.
(NSAIDs) are recommended for pain control. At the last follow-up, four months since the original arthrocentesis, the patient reported his pain level as VAS 1-2/10.

\section{DISCUSSION}

HOA is a syndrome clinically characterized by abnormal skin and periosteal proliferation of the distal extremities [1]. Patients with HOA may be asymptomatic or present various clinical signs. The classical triad for HOA is digital clubbing, periostosis, and synovial effusions. Patients often present with periostosis, although not all patients have digital clubbing, joint pain, or effusion [5]. Patients may feel a burning sensation and bone pain as the disease progresses [1]. Clinical diagnosis may be challenging because the symptoms are similar to those of connective tissue diseases or inflammatory arthritis. In this case, the patient showed clinical signs of periostosis as pain and swelling of both legs and joint effusion of both knees but did not have clubbing of the fingers or toes.

The mechanism of pathogenesis of HOA is unclear. One possibility is a neurogenic pathway model. The vagus nerve innervates the organ with disease and induces a neural reflex that may cause vasodilation followed by increased blood flow to the extremities [6]. Another possibility is a humoral pathway. Hypoxia in patients with lung disease induces cytokines and growth factors such as vascular endothelial growth factor (VEGF), platelet-derived growth factor, and prostaglandin E2 (PGE2). These molecules induce development of new periosteal bone formation [7].

Primary HOA is a rare hereditary disease representing only $3 \%$ of all cases of HOA [2]. Also known as pachydermoperiostosis, it is characterized by early onset of clubbing and thickening of the skin of the face. Primary HOA involves mutations of the 15-hydroxyprostaglandin dehydrogenase gene and the solute carrier organic anion transporter family member 2Al gene. Mutation of these genes impairs the ability to degrade PGE2. Elevation of PGE2 results in overexpression of VEGF. In consequence, excessive new bone formation appears by osteoblasts [8].

Secondary HOA is primarily associated with abnormal lung function because of lung cancer, interstitial lung disease, sarcoidosis, chronic obstructive pulmonary disease, pulmonary infections, abscess, empyema, or mesothelioma. Even with undamaged lungs, cyanotic heart disease can cause HOA by excluding the lungs from systemic circulation $[1,3]$. The most common cause of secondary HOA is non- 
small cell lung cancer. The incidence of HOA in lung cancer is reported as $4 \%$ to $17 \%$ [5]. It may appear as a generalized or localized form involving only one or two extremities. The generalized form is caused by systemic disease, while the localized form is associated with endothelial injury, such as arterial aneurysm, arterial graft infection, or a functioning arteriovenous fistula [9]. HOA has been rarely reported as a paraneoplastic syndrome in other malignancies including gastrointestinal, hematologic, nasopharyngeal, melanoma, breast, and renal cell cancer $[3,4]$. Renal cell cancer was the cause of HOA in this case.

Imaging evaluation can be a major tool for diagnosing HOA because serological tests are not reliable [3]. Plain radiographs are used as the first modality. Periostosis along the shaft of tubular bones is the key feature found on plain radiographs. The most commonly affected bones are the tibia, fibula, radius and ulna [3]. They may also present bony deformities and soft tissue swelling. Long standing clubbing can result in osseous resorptions of the fingers and toes. These bony changes appear first in the toes before they manifest in the fingers [1]. Joint involvement can also appear on plain radiographs as synovial effusions, joint space narrowing, erosions, or periarticular osteopenia [3].

Magnetic resonance imaging (MRI) can also be used to show periosteal reactions, osseous proliferation at the ligaments and tendons in later stages, and specific soft tissue changes in periarticular swelling sites. Also, MRI can be useful for identifying synovial effusion $[3,10]$.

Bone scintigraphy is more sensitive for detecting HOA than radiography alone [11]. Patients with known malignancies are often found to have HOA on bone scintigraphy [3]. Significant radiotracer uptake is shown at the periosteum along the cortical margin of long tubular bones [12]. This modality can be used to estimate the response to therapy if findings resolve after treatment [13]. Similar to bone scintigraphy, positron emission tomography with $18 \mathrm{~F}$ isotopes can also be used to show the hypermetabolic activity along the long tubular bones. In this case, periosteal reactions observed on simple radiologic studies and bone scintigraphy were diagnostic for HOA.

Radiological signs of periosteal reactions can appear in various conditions including thyroid acropachy, leukemia, lymphoma, hypervitaminosis A, venous stasis, and use of medications such as voriconazole. The type and distribution of periosteal reaction varies in these conditions. Bilaterally symmetrical involvement of the appendicular skeleton characterizes HOA [1,3]. Identifying underlying disease and re- viewing medical history may help in patient diagnosis and treatment. In this case, the patient had known renal cell cancer, an absence of thyroid diseases, hematologic malignancies, or venous insufficiency, and no use of retinoids or voriconazole.

Because the prognosis and mortality of secondary HOA are associated with underlying disease, treatment should be focused on the primary disease, even considering surgical resection of the primary tumor. Symptomatic treatment options include analgesics, such as NSAIDs. In some cases, bisphosphonate and octreotide provided effective symptomatic treatment of bone pain [14]. Also, truncal vagotomy has shown symptomatic relief for refractory patients [15]. In this case, aspiration of knee joint fluid and intra-articular injection for pain were found to be effective. The patient is undergoing chemotherapy for the renal cell cancer after surgery on the primary and colon metastasis sites.

In summary, this case demonstrates that HOA should be considered in patients with malignancies other than lung cancer when they have bone or joint pain of the extremities, even without digital clubbing. Treating the underlying disease and pain management are both important. Pain management options in patients with HOA include analgesic medications such as NSAIDs, bisphosphonate, octreotide, surgery of the original tumor, and sympathectomy. As in this case, joint aspiration and intra-articular injection can be a treatment option for patients with joint effusions.

\section{CONFLICTS OF INTEREST}

No potential conflict of interest relevant to this article was reported.

\section{DATA AVAILABILITY STATEMENT}

The datasets generated during and/or analyzed during the current study are available from the corresponding author on reasonable request.

\section{AUTHOR CONTRIBUTIONS}

Conceptualization: Hwa-Yong Shin. Writing - original draft: Kyung Seo Oh. Writing - review \& editing: Kyung Seo Oh, Seung Young Lee, Hwa-Yong Shin. Supervision: Se-Hee Min, Choongun Ryu, Hwa-Yong Shin. 


\section{ORCID}

Kyung Seo Oh, https://orcid.org/0000-0002-8827-975X

Seung Young Lee, https://orcid.org/0000-0003-2734-1342

Se-Hee Min, https://orcid.org/0000-0002-0945-0177

Choongun Ryu, https://orcid.org/0000-0001-9234-3534

Hwa-Yong Shin, https://orcid.org/0000-0002-8721-3070

\section{REFERENCES}

1. Pineda C, Martínez-Lavín M. Hypertrophic osteoarthropathy: what a rheumatologist should know about this uncommon condition. Rheum Dis Clin North Am 2013; 39: 383-400.

2. Diren HB, Kutluk MT, Karabent A, Göçmen A, Adalioğlu G, Kenanoğlu A. Primary hypertrophic osteoarthropathy. Pediatr Radiol 1986; 16: 231-4.

3. Yap FY, Skalski MR, Patel DB, Schein AJ, White EA, Tomasian A, et al. Hypertrophic osteoarthropathy: clinical and imaging features. Radiographics 2017; 37: 157-95.

4. Meyer HJ, Leifels L, Bach AG, Surov A. Secondary hypertrophic osteoarthropathy caused by non-pleural or pulmonary tumors. Medicine (Baltimore) 2017; 96: e7985.

5. Izumi M, Takayama K, Yabuuchi H, Abe K, Nakanishi Y. Incidence of hypertrophic pulmonary osteoarthropathy associated with primary lung cancer. Respirology 2010; 15: 809-12.

6. Treasure T. Hypertrophic pulmonary osteoarthropathy and the vagus nerve: an historical note. J R Soc Med 2006; 99: 388-90.

7. Yao Q, Altman RD, Brahn E. Periostitis and hypertrophic pul- monary osteoarthropathy: report of 2 cases and review of the literature. Semin Arthritis Rheum 2009; 38: 458-66.

8. Yuan L, Chen L, Liao RX, Lin YY, Jiang Y, Wang O, et al. A common mutation and a novel mutation in the HPGD gene in nine patients with primary hypertrophic osteoarthropathy. Calcif Tissue Int 2015; 97: 336-42.

9. Ahrenstorf G, Rihl M, Pichlmaier MA, Rosenthal H, Witte T, Schmidt RE. Unilateral hypertrophic osteoarthropathy in a patient with a vascular graft infection. J Clin Rheumatol 2012; 18: 307-9.

10. Capelastegui A, Astigarraga E, García-Iturraspe C. MR findings in pulmonary hypertrophic osteoarthropathy. Clin Radiol 2000; 55: 72-5.

11. Rutherford GC, Dineen RA, O'Connor A. Imaging in the investigation of paraneoplastic syndromes. Clin Radiol 2007; 62: 1021-35.

12. Santhosh S, Bhattacharya A, Bhadada S, Kaur R, Singh M, Mittal BR. Three-phase skeletal scintigraphy in pachydermoperiostosis. Clin Nucl Med 2011; 36: e199. -201.

13. Shih WJ. Pulmonary hypertrophic osteoarthropathy and its resolution. Semin Nucl Med 2004; 34: 159-63.

14. Nguyen S, Hojjati M. Review of current therapies for secondary hypertrophic pulmonary osteoarthropathy. Clin Rheumatol 2011; 30: 7-13.

15. Ooi A, Saad RA, Moorjani N, Amer KM. Effective symptomatic relief of hypertrophic pulmonary osteoarthropathy by video-assisted thoracic surgery truncal vagotomy. Ann Thorac Surg 2007; 83: 684-5. 